\title{
Perspectives on Thalamic and Hypothalamic Tumors of Childhood
}

\author{
David G. McLone, Editor-in-Chief
}

Fred Epstein has again hosted a symposium to look at the present state of the management of a problem in pediatric neurosurgery.

In Fred's own words: hypothalamic and thalamic tumors of childhood pose distinct clinical challenges. Most hypothalamic astrocytomas are biologically indolent, but cause significant neurologic deficits affecting vision, hormonal function, motor control and cognition. Although these tumors may be controllable for a period of time, they are rarely curable. Thalamic gliomas are biologically more aggressive and require more intensive therapy. Recent advances in neuroimaging, chemotherapy, radiotherapy and neurosurgery have dramatically altered our therapeutic options. However, selection and prioritization of the various therapeutic modalities for patients with both low-grade chiasmatic/hypothalamic and high-grade thalamic astrocytomas remains controversial.

The purpose of this meeting is to bring together a group of clinicians and scientists who represent a range of disciplines and have extensive experience and expertise in managing children with diencephalic gliomas. Several basic scientists will liven the discussion regarding the possible etiologies, methods of diagnosis, treatment priorities and future directions for clinical research. Major issues that will be addressed include: the contrasting tumor biology of hypothalamic and thalamic gliomas; the selection of patients who require early therapeutic intervention and/or histologic documentation at diagnosis; the roles and priorities of neurosurgery, radiotherapy and chemotherapy, and strategies to minimize late effects of therapy in patients destined to experience long-term survival.

The papers from this symposium will be published over the next several months under Perspectives.

\section{KARGER \\ Fax + 41613061234}

E-Mail karger@karger.ch www.karger.com (c) 2000 S. Karger AG, Basel

1016-2291/00/0323-0113\$17.50/0

Accessible online at: www. karger.com/journals/pne 